See Article page 30.

\section{Commentary: Vasa vasorum dysfunction and acute aortic syndromes: When guidelines do not follow the evolution of knowledge}

\author{
Antonio M. Calafiore, MD, ${ }^{a}$ Kostas Katsavrias, MD, ${ }^{b}$ \\ Massimo Di Marco, MD, ${ }^{\mathrm{c}}$ Stefano Guarracini, MD, ${ }^{\mathrm{d}}$ \\ and Michele Di Mauro, $\mathrm{PhD}, \mathrm{MD}^{\mathrm{d}, \mathrm{e}}$
}

The aorta is a very strong structure. Aortic rupture does not occur if the intraluminal pressure ranges from 790 to $2070 \mathrm{~mm} \mathrm{Hg} .{ }^{1}$ Robertson and Smith, injecting water into the media of 42 fresh human aortas, found that the lowest pressure required to exceed the cohesive strength of the media was $273 \mathrm{~mm} \mathrm{Hg}$ and the highest was $975 \mathrm{~mm} \mathrm{Hg}$, with a mean of $566 \mathrm{~mm} \mathrm{Hg.}{ }^{2}$ Therefore, the aorta is highly resistant to rupture or dissection.

In this issue of the Journal, Haverich and Boyle ${ }^{3}$ repropose an appealing unifying theory on the genesis of aortic intramural hematoma (AIMH) and aortic dissection (AD). Vasa vasorum dysfunction is the link between these entities, which are seen as progression of one to the other. Rupture and bleeding of the vasa vasorum into the media is the cause of AIMH. It can remain limited to the thickness of the aorta or cause an intimal tear, which is at the basis of classic AD.

The vasa vasorum fill during diastole as in the coronary circulation. Thus, an increase in arterial diastolic pressure

\footnotetext{
From the ${ }^{a}$ Department of Cardiovascular Sciences, Gemelli Molise, Campobasso, Italy; ${ }^{b}$ Department of Cardiac Surgery, Henry Durant Hospital, Athens, Greece; ${ }^{\mathrm{c}}$ Department of Cardiology, "Santo Spirito" Hospital, Pescara, Italy; ${ }^{\mathrm{d}}$ Department of Cardiology, "Pierangeli" Hospital, Pescara, Italy; and ${ }^{\mathrm{e}}$ Cardio-Thoracic Surgery Unit, Heart and Vascular Centre, Maastricht University Medical Center, Cardiovascular Research Institute Maastricht, Maastricht, The Netherlands.

Disclosures: The authors reported no conflicts of interest.

The Journal policy requires editors and reviewers to disclose conflicts of interest and to decline handling or reviewing manuscripts for which they may have a conflict of interest. The editors and reviewers of this article have no conflicts of interest.

Received for publication Dec 19, 2020; revisions received Dec 19, 2020; accepted for publication Dec 22, 2020; available ahead of print Jan 21, 2021.

Address for reprints: Antonio M. Calafiore, MD, Department of Cardiovascular Diseases, Gemelli Molise, Largo A Gemelli 1, 86100, Campobasso, Italy (E-mail: am. calafiore@gmail.com).

JTCVS Open 2021;5:33-4

2666-2736

Copyright (C) 2020 The Authors. Published by Elsevier Inc. on behalf of The American Association for Thoracic Surgery. This is an open access article under the CC BY license (http://creativecommons.org/licenses/by/4.0/).

https://doi.org/10.1016/j.xjon.2020.12.015
}

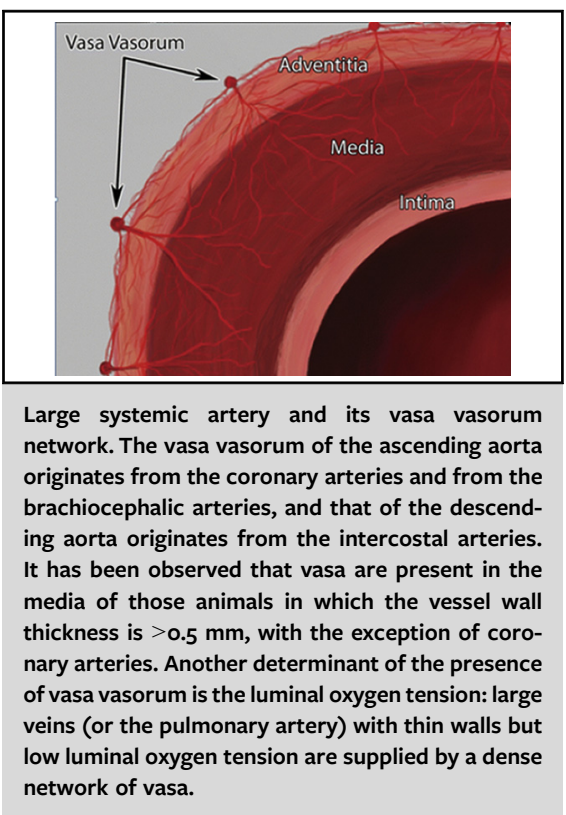

CENTRAL MESSAGE

Vasa vasorum dysfunction can be the unpredictable event that causes intramural hemorrhages and intimal tears, causing acute aortic syndromes even with a mild or moderate increase in aortic size.

in the host vessel results in reduced perfusion, ${ }^{4}$ which can cause vessel wall hypoxia and neoangiogenesis, with the neovessels more fragile and prone to bleed. Hypertension also can reduce blood flow by distortion or compression of the vasa, generating changes in the walls of the vasa vasorum with critical ischemia and necrosis of the media. Other factors (eg, inflammation) can induce aberrant and adverse remodeling of the aortic wall, including smooth muscle cell loss in the media and extracellular matrix degradation in the media and the adventitia. The consequence is chronic dilation of the aorta, but an acute aortic syndrome (AAS) can superimpose at any moment.

The guidelines for prophylactic surgery of ascending aortic aneurysms include only the aortic size, with a cutpoint of $55 \mathrm{~mm}$ in non-Marfan nonbicuspid valve aortas. ${ }^{5}$ Tozzi and colleagues ${ }^{6}$ found that $87.7 \%$ of patients with $\mathrm{AD}$ had a preoperative aortic size $<45 \mathrm{~mm}$, and that a threshold of $55 \mathrm{~mm}$ excluded $\sim 99 \%$ of patients with $\mathrm{AD}$ 
from prophylactic surgery. The same findings have been reported by others. ${ }^{7}$ Aortic size is only a surrogate marker, often unreliable, of catastrophic events, and the guidelines need to recognize the difficulty of linking aortic size to AAS. An update of the natural history of ascending aortic aneurysms from the Yale team found that the hinge point for rupture or dissection was reduced from $60 \mathrm{~mm}$ in an earlier study of 230 patients to $52.5 \mathrm{~mm}$ in a study of 3400 patients. ${ }^{8}$ Other unpredictable events, including vasa vasorum dysfunction, can occur at any time. Genetic screening in individuals with nonsyndromic aortic aneurysms remains a work in progress, and clinical implications are not widely accepted. ${ }^{9,10}$ As it is impossible to foresee which aorta at which size could undergo an acute event, reducing the aortic size for prophylactic surgery is our only tool for treating more patients before AAS occurs.

\section{References}

1. Oppenhein F. Gibt es eine spontanruptur der gesunden aorta und wie kommt sie zustande? Munchen Med Wchnschr. 1928;65:1234-7.

2. Robertson JS, Smith KV. Analysis of certain factors associated with production of experimental dissection of aortic media in relation to pathogenesis of dissecting aneurysm. J Path Bact. 1948;60:43-9.
3. Haverich A, Boyle EC. Aortic dissection is a disease of the vasa vasorum J Thorac Cardiovasc Surg Open. 2021:5:30-2.

4. Scotland RS, Vallance PJ, Ahluwalia A. Endogenous factors involved in regulation of tone of arterial vasa vasorum: implications for conduit vessel physiology. Cardiovasc Res. 2000;46:403-11.

5. Erbel R, Aboyans V, Boileau C, Bossone E, Di Bartolomeo R, Eggebrecht H, et al. 2014 ESC guidelines on the diagnosis and treatment of aortic diseases: document covering acute and chronic aortic diseases of the thoracic and abdominal aorta of the adult. The task force for the diagnosis and treatment of aortic diseases of the European Society of Cardiology (ESC). Eur Heart J. 2014;35: 2873-926.

6. Tozzi P, Gunga Z, Niclauss L, Delay D, Roumy A, Pfister R, et al. Type A aortic dissection in aneurysms having modelled pre-dissection maximum diameter below $45 \mathrm{~mm}$ : should we implement current guidelines to improve the survival benefit of prophylactic surgery? Eur J Cardiothorac Surg. October 2, 2020 [Epub ahead of print].

7. Rylski B, Branchetti E, Bavaria JE, Vallabhajosyula P, Szeto WJ, Milewski RK, et al. Modeling of predissection aortic size in acute type A dissection: more than $90 \%$ fail to meet the guidelines for elective ascending replacement. J Thorac Cardiovasc Surg. 2014;148:944-8.e1.

8. Ziganshin BA, Zafar MA, Elefteriades JA. Descending threshold for ascending aortic aneurysmectomy: is it time for a "left-shift" in guidelines? J Thorac Cardiovasc Surg. 2019;157:37-42.

9. Brownstein AJ, Ziganshin BA, Kuivaniemi H, Body SC, Bale AE, Elefteriades JA. Genes associated with thoracic aortic aneurysm and dissection: an update and clinical implications. Aorta (Stamford). 2017;5:11-20.

10. Baikoussis NG, Apostolakis EE, Papakonstantinou NA, Siminelakis SN, Arnaoutoglou H, Papadopoulos G, et al. The implication of vasa vasorum in surgical diseases of the aorta. Eur J Cardiothorac Surg. 2011;40:412-7. 